\title{
Interdisciplinary Research Approaches on Environment: A Matter of Sustainable Development in Higher Education.
}

\begin{abstract}
T.Phani Madhavi
Professor, Department of Civil Engineering, Nalanda Institute of Engineering \& Technology, Guntur District, Andhra Pradesh, India
\end{abstract}

\begin{abstract}
Interdisciplinary research is imperative for solving several environmental problems. The interdisciplinary approach in education provides opportunities to students to explore interconnections among wide range of subject areas. Interdisciplinary environmental education furnish the future environmental engineers and scientists with sufficient wealth of information, ideas and respect towards environment for societal progress. A large amount of research is essential to understand the movement of water, air, physical and chemical properties of various substances in environment, their interactions and its impact on environmental systems. This paper was aimed towards the interdisciplinary research approaches on several environmental issues and to implementation of sustainable development in higher education. The objective of environmental research is to move towards sustainability and for the improvement of human welfare. Government policies and educational institutions plays a vital role to control the environmental degradation. The scope of environmental issues has grown greatly in the past decade and will continue to expand largely in future. There is a need for continuous scrutiny and modification in the structure and content in the environmental curricula in higher education in order to address the present and future challenges and to achieve environmental sustainability.
\end{abstract}

Keywords: Interdisciplinary Approach, Environment, Sustainable Development, Higher Education. 